\title{
ALL REASONS ARE FUNDAMENTALLY FOR ATTITUDES
}

\section{Conor McHugh and Jonathan Way}

$\Lambda^{\mathrm{s}}$

RATIONAL AGENTS, we are governed by reasons. The fact that there is beer at the pub might be a reason to go there and a reason to believe you will enjoy it. Facts reported on the news might be reasons to believe there is suffering in a war zone and donate to charity. Specifically, these are normative reasons - considerations that rationally support responses we can give in light of them. They must be distinguished from motivating reasons: reasons for which, or considerations in light of which, we respond. Motivating reasons can be normative reasons, but they need not be: the reasons for which we think or do things may not really support those responses. Hereafter by "reasons" we mean normative reasons unless indicated.

As the above examples illustrate, there are reasons for both action and belief. But although much work on reasons focuses primarily on action and belief, there are many other responses for which there seem to be reasons. In particular, many attitudes besides belief - for example, desire, regret, admiration, contempt, fear, gratitude, and blame — seem subject to reasons. This diversity raises questions about how reasons for different responses relate to each other. Might certain such reasons be more fundamental than others? Should certain reasons and not others be treated as paradigmatic?

Often, reasons for action are at least implicitly treated as the fundamental or paradigmatic case. This can be seen, for example, in the tendency of philosophers to find it puzzling that reasons for attitudes seem not to satisfy certain conditions on reasons for action. For example, it is plausible that there is a reason to act in some way only if acting in that way is under your voluntary control. But attitudes are rarely, perhaps never, under our voluntary control. And it is plausible that, at least very often, when there is a reason to act in some way, so acting will promote or realize some value. But it seems easy to imagine cases in which there is a reason for an attitude but having that attitude will not promote or realize any value. Such observations have led some to argue that reasons for attitudes do, despite appearances, meet these conditions; they have led others 
to deny that there can be reasons for attitudes. ${ }^{1}$ But the thought that these conditions must be met by all reasons seems to assume that reasons for action are paradigmatic. And we might instead question that assumption.

Our aim here is to explore and defend an alternative approach. We suggest that reasons for attitudes are fundamental, and reasons for action are both derivative and, in certain ways, idiosyncratic. More specifically, we claim that reasons for action are derivative from reasons for intention. For most of the paper we focus on this more specific claim, but we point out that if it is defensible then it lends considerable plausibility to the general claim that all reasons are fundamentally for attitudes.

In section 1, we outline both our general and our more specific claim. In section 2, we offer two arguments for the more specific claim, based on two plausible (though not uncontentious) assumptions about reasons: they are potential premises of good reasoning and they are capable of being responded to. In section 3 , we consider objections. In section 4 , we return to the more general claim and sketch some ways in which it is significant for theorizing about reasons.

\section{TWO HYPOTHESES}

We will defend the following claim:

General Hypothesis: All reasons are fundamentally reasons for attitudes.

A reason for a non-attitude is fundamentally a reason for an attitude if what it is to be a reason for the non-attitude is to be a reason for an attitude. As we might also say, such reasons are "nothing over and above" reasons for attitudes. It is a contested question how best to understand such locutions - for instance, whether in terms of identity, constitution, grounding, or essence. We will just assume they are in good order.

According to the General Hypothesis, if there are reasons for action then they are fundamentally reasons for some attitude. How could this be? Well, reasons for action seem closely related to reasons for intention. Very often, at least, a reason for one seems to be a reason for the other. So a natural further claim for a proponent of the General Hypothesis to make is this:

1 For the first reaction, with respect to reasons for belief, see Foley, The Theory of Epistemic Rationality; Ryan, "Doxastic Compatibilism and the Ethics of Belief"; Steglich-Peterson, "How to Be a Teleologist about Epistemic Reasons”; Steup, "Doxastic Freedom”; and Weatherson, "Deontology and Descartes's Demon." For the second, see especially Maguire, "The Value-Based Theory of Reasons" and "There Are No Reasons for Affective Attitudes"; but cf. also Gluer and Wikforss, "Against Content Normativity"; and Papineau, "Normativity and Judgement." 
Special Hypothesis: Reasons for action are fundamentally reasons for intention. ${ }^{2}$

Are there other sorts of reason that challenge the General Hypothesis? Well, in ordinary talk we are happy to say that you have reason to be at the pub now (since it is past 6 p.m.), or reason to be stronger (since you are running a marathon soon), or reason to be able to speak French (since you are in Montreal). But being at the pub, being stronger, and being able to speak French are neither attitudes nor actions.

However, it is very natural to reinterpret these claims in terms of reasons for action or attitudes. You have a reason to be in the pub insofar as you have a reason to get there or to want to be there. You have a reason to be stronger, or to be able to speak French, insofar as you have reasons to desire, and to bring it about, that you are stronger or able to speak French. This reinterpretation is natural because reasons are for responding to. We cannot respond to a reason to be somewhere or to have an ability except by acting and having attitudes. So it is natural to think that what underlies talk of such reasons are reasons to act and have attitudes.

This suggests that we should be cautious about taking ordinary talk of reasons at face value. This opens the door for the Special Hypothesis. Nonetheless, it is less natural to think that you have reasons to act only insofar as you have reasons to intend-indeed, things might seem to be the other way around. ${ }^{3}$ We thus take reasons for action to pose the most significant challenge to the General Hypothesis. In the rest of this paper, we will make a case for the Special Hypothesis. Assuming that what we have just said is right, the main obstacle to acceptance of the General Hypothesis will thereby have been removed. Before presenting that case, we offer some clarifications to make the Special Hypothesis more precise.

The Special Hypothesis holds that reasons to act are fundamentally reasons to intend. There are different ways this could be so, but on the version of the Special Hypothesis we will work with:

Special Hypothesis, Simple Version: For $p$ (a fact) to be a reason to $\phi$ (an act type) is for $p$ to be a reason to intend to $\phi$. For $p$ to be a reason to not- $\phi$ is for $p$ to be a reason to intend to not- $\phi .{ }^{4}$

2 Gibbard (Wise Choices, Apt Feelings, 38-39), Hedden (Reasons without Persons, ch. 6), Portmore (Commonsense Consequentialism, 63), Scanlon (What We Owe to Each Other, 21), and Smith ("The Ideal of Orthonomous Agency, or the How and Why of Buck-Passing," 60) endorse claims like this. Gibbard, Portmore, Scanlon, and Smith do not defend them at length. Hedden's view, which concerns what he calls the "rational ought," depends on a kind of mentalism that we would reject as applied to reasons.

3 Dancy says that "it seems just obvious" that reasons to intend derive from reasons to act (Practical Shape, 4).

4 Versions of the Special Hypothesis vary, for instance, on the relation between the act type 
Talk of "actions" can refer to act types or token actions. Act types are types of things - events or perhaps processes - that can be done intentionally (including, for our purposes, omissions). Token actions are instances of these types. Not all act types are things that must be done intentionally: you might bring your book to work unintentionally because you left it in your bag, or press the button unintentionally while reaching for your coffee. A reason to act supports a certain act type, such as bringing the book to work or pressing the button, rather than any token action. Compliance with the reason requires that some token of the relevant type occur.

Intention is a type of attitude: a persisting psychological state with a content or object. It is closely related to action, in at least the following respects. First, intentions take act types, or propositions about them, as their objects. Second, action is the telos of intention. To intend is to aim to act, and to execute an intention is to act intentionally. A future-directed intention to $\phi$ tends to persist until it becomes present directed. A present-directed intention to $\phi$ manifests itself in presently trying to $\phi$, which, if successful, counts as, or helps constitute, intentional $\phi$-ing. Some philosophers hold, further, that intentionally $\phi$-ing requires intending to $\phi$, or at least some relevant intention. ${ }^{5}$ We will not assume this. ${ }^{6}$

It is sometimes claimed that forming an intention can itself be an action-a mental act of deciding. Similarly, it is sometimes claimed that beliefs can be formed through acts of judgment. Arguably, however, decisions and judgments are not actions in the sense presently at issue, since they cannot be performed intentionally. ${ }^{7}$ If so, the Special Hypothesis does not apply to them. Given the intimate relations between decision and intention on the one hand, and between judgment and belief on the other, we take it that reasons for decisions and judgments can instead be treated as reasons for attitudes, and so as falling under the General Hypothesis. We will not explore this matter further here; instead we focus on reasons for act types in the sense defined. Note that this includes some mental act types, such as imagining a hippopotamus or calculating the square

for which there is a reason and the content of the intention for which that reason is a reason.

5 The first of these claims is the "Simple View"; the second is the "Single Phenomenon View." See Bratman, Intentions, Plans, and Practical Reason.

6 We hope these remarks on action and intention are relatively uncontroversial; they fit with, but do not presuppose, the influential "planning theory" of intention (Bratman, Intentions, Plans, and Practical Reason). For general discussion, see Setiya, "Intention"; and Wilson and Shpall, "Action."

7 That is, you cannot intentionally decide on a particular course of action or judge a particular proposition to be true. Many authors who regard judging and deciding as acts accept this point, e.g., Hieronymi, "Controlling Attitudes"; and McHugh, "Judging as a Non-Voluntary Action." 
root of 441. The Special Hypothesis applies to reasons for such mental act types, though our examples will mainly be of physical act types.

Reasons and intentions are indexed to times, twice over. You might now have reason to go to the pub now, or now have reason to go to the pub later. ${ }^{8}$ Similarly, you might now intend to go to the pub now, or later. How should the Special Hypothesis accommodate this? We shall take it to say that a reason (at $\left.t_{1}\right)$ to $(\phi$ at $\left.t_{2}\right)$ is a reason $\left(\right.$ at $\left.t_{1}\right)$ to intend $\left(\right.$ at $\left.t_{1}\right)$ to $\left(\phi\right.$ at $\left.t_{2}\right)$. We will not generally need to take care over this, though issues about time will be relevant in section 3.3.

The Special Hypothesis takes reasons to act to be nothing over and above reasons to intend. It is plausible that, as such, you are criticizable with respect to reasons to act only insofar as you are criticizable with respect to reasons to intend. Compare: you are criticizable for not being at the pub only insofar as you are criticizable for not going there. ${ }^{9}$ We grant, for the sake of argument, that the Special Hypothesis has this implication. To illustrate, compare Jack and Jill, each of whom would benefit from $\phi$-ing, has no reason not to $\phi$, and knows all this. Jack fails to even intend to $\phi$. Jill forms and maintains the intention to $\phi$, and tries her best to $\phi$, but fails. Here, only Jack is rationally criticizable for his intentions. The Special Hypothesis thus implies that only Jack is rationally criticizable for his actions. This is a plausible verdict. We will call Jack irrational, silly, perverse, and so on. We might call Jill clumsy or inept, but insofar as she tried her best we will not call her irrational or the like. ${ }^{10}$

As characterized, the Special Hypothesis implies not only that all reasons to act are reasons to intend but also that all reasons to intend are reasons to act. This might be disputed because of examples such as Kavka's "toxin puzzle," where there is a large reward for merely intending to drink an unpleasant but otherwise harmless toxin. ${ }^{11}$ However, the literature divides on such examples. Some hold that such considerations are not genuine reasons to intend, but rather reasons to want to intend or bring it about that you intend. Others hold that they are genuine but "wrong-kind" reasons to intend. For simplicity, we will assume the first view here. Those who prefer the second can amend the Special Hypothesis to say that reasons to act are fundamentally right-kind reasons to intend. ${ }^{12}$

8 For discussion see Kiesewetter, The Normativity of Rationality, 215ff.

9 Cf. Broome, Rationality through Reasoning. We do not deny that reasons that are derivative in weaker senses might ground criticism. For instance, you can be criticized for failing to act on an instrumental reason, even if you end up achieving the end from which this reason derives. One might think that in other cases we can be rationally criticizable irrespective of our intentions. We consider this below (section 3.3).

Kavka, “The Toxin Puzzle."

For the first view, see, e.g., Gibbard, Wise Choices, Apt Feelings; McHugh and Way, "Fitting- 
The Special Hypothesis contrasts with views that take reasons to act and reasons to intend to be independent and views that take reasons to intend to be, or at least to derive from, reasons to act. We take the latter to be the more common and plausible alternative. On the most popular version of this view, reasons to intend are instrumental: there is reason to intend to $\phi$ just when and because there is reason to $\phi$ and intending to $\phi$ promotes $\phi$-ing. ${ }^{13}$ Since this seems the most natural story about how reasons to intend might derive from reasons to act, we will take it to be the main alternative to our account. Note that this view implies that not all reasons to act are reasons to intend. In a case in which intending to $\phi$ does not promote $\phi$-ing-for instance because you are going to $\phi$ regardless of whether you intend to-a reason to $\phi$ is not a reason to intend to $\phi$. We return to this below.

Another alternative to the Special Hypothesis takes reasons for intentional action to be prior to both reasons for action (which, recall, need not be intentional) and reasons to intend. For instance, perhaps to be a reason to $\phi$ is to be a reason to intentionally $\phi$. For simplicity, and because we do not know of any defenses of this view, we shall mostly ignore it. ${ }^{14}$ However, our arguments for the Special Hypothesis might be developed to support this view, given certain further assumptions (see especially section 2.2 ). It would also face some of the same objections as the Special Hypothesis, and can make some of the same replies. So the paper's arguments should be of interest to those considering such a view.

\section{ARGUMENTS FOR THE SPECIAL HYPOTHESIS}

The example of Jack and Jill provides some initial motivation for the Special Hypothesis. In this section we offer two further arguments for it.

Our arguments will make two assumptions about reasons. First, we assume that it is a central truth about reasons that they are potential premises of good reasoning. Second, we assume that reasons are subject to a response constraint:

ness First"; Parfit, On What Matters; and Shah "How Action Governs Intention." For the second, see, e.g., Hieronymi, "The Wrong Kind of Reason"; Howard, "The Fundamentality of Fit"; and Schroeder, Slaves of the Passions.

The Special Hypothesis may require further amendments too. For example, if you think "reason to $\phi$ " implies "can $\phi$ " but "reason to intend to $\phi$ " does not, you might add the condition that the agent can perform the action. For simplicity we ignore this possibility.

13 Cf. Heuer, "Reasons to Intend"; Pink, The Psychology of Freedom; and Kolodny, "The Myth of Practical Consistency."

14 However, the view may appeal to defenders of the view that intentional action is prior to intention. See, e.g., Thompson, Life and Action; McDowell, "Some Remarks on Intention in Action"; and, for discussion, Setiya, "Intention." 
normative reasons must be capable of being responded to-of being our motivating reasons. These assumptions are popular and plausible. ${ }^{15}$ Both are motivated by the attractive idea that the point of reasons is to guide us. The way in which reasons most explicitly guide us is through reasoning: thus we should expect reasons to be potential premises of good reasoning. And a reason you cannot respond to is not one that can guide you. While neither assumption is uncontentious, we cannot defend them further here; instead we aim to show that if they are granted, they naturally lead to the Special Hypothesis.

\subsection{The Response Constraint}

Our first argument has two parts. We first argue that the response constraint supports the claim that any reason to $\phi$ is also a reason to intend to $\phi$. We then show that this claim supports the Special Hypothesis.

The response constraint tells us that a reason for acting is a reason that can be acted on: if $p$ is a (normative) reason for you to $\phi$, you can $\phi$ for the (motivating) reason that $p .{ }^{16}$ But acting for a reason, we suggest, entails acting from an intention. In particular, you act for a reason only if you execute an intention held for (based on) that reason. ${ }^{17}$ To illustrate, suppose you intend to take a book to work with you, for the reason that the reading group meets this afternoon (that is, your intention is held for this reason-what you intend is not to take-the-book-forthis-reason, but simply to take the book). If you take the book by executing this intention then you take the book for the reason that the reading group meets this afternoon. But if you take the book without executing this intention, you do not. For example, if you take the book by picking up your bag, which, unbeknownst to you, contains the book, then, although you take the book, and intend to do so for the reason that the reading group meets this afternoon, you do not take the book for the reason that the reading group meets this afternoon.

15 For versions of the first assumption, and responses to objections, see Asarnow, "Rational Internalism"; Hieronymi, "The Wrong Kind of Reason”; McHugh and Way, "Fittingness First”; Paakkunainen, "Can There Be Government House Reasons for Action?”; Setiya, Reasons without Rationalism; Schroeder, Slaves of the Passions; Silverstein, "Reducing Reasons"; Williams, "Internal and External Reasons." For versions of the second, and responses to objections, see Kiesewetter, The Normativity of Rationality; Kolodny, "Why Be Rational?”; Lord, The Importance of Being Rational; Parfit, On What Matters; Raz, From Normativity to Responsibility; Shah, "A New Argument for Evidentialism"; Way and Whiting, "Reasons and Guidance (or, Surprise Parties and Ice Cream)"; and Williams, "Internal and External Reasons." In the rest of this section, we generally allow context to disambiguate between motivating and normative reasons.

17 Cf. Davidson, "Intending"; Setiya, Reasons without Rationalism; and Hieronymi, "Reasons for Action." 
Thus, acting for a reason entails acting from an intention held for that reason. But in general, if you base an attitude on a consideration, you treat that consideration as a normative reason for that attitude. So in intending to $\phi$ for the reason that $p$, you treat $p$ as a reason to intend to $\phi$. Furthermore, if it is a reason to $\phi$ then it is appropriate that you treat it in this way. ${ }^{18}$

Thus, if $p$ is a reason to $\phi$ then $p$ can be appropriately treated as a reason to intend to $\phi$. But if it is appropriate to treat something as a reason to intend to $\phi$, then it is a reason to intend to $\phi$. Reasons are considerations that can appropriately play certain roles in our thinking and reasoning. To treat a consideration as a reason is to treat it as an appropriate occupant of such a role. If it is appropriate to treat it in this way, then it is an appropriate occupant of this role-that is, it is a reason. (Compare: if a precedent is appropriately treated as legally authoritative, then it is authoritative.)

Let us sum up the argument thus far. Reasons for action can be acted on. You act on a reason only if you intend for that reason. In doing so you treat it as a reason for intention, and appropriately so. But a consideration that can be appropriately treated as a reason for intention is one. So a reason to $\phi$ is also a reason to intend to $\phi$.

If correct, this shows that all reasons to act are also reasons to intend. The Special Hypothesis offers a straightforward explanation: all reasons to act are reasons to intend because to be a reason to act is to be a reason to intend. Of course, by itself this only provides limited support for the Special Hypothesis, since this generalization might be explained in other ways. However, as we noted, the view that reasons to intend are instrumental, which appears to be the main alternative to the Special Hypothesis (section 1), is committed to denying, and thus cannot explain, the fact that all reasons to act are reasons to intend. As we discuss in more detail in section 3 , there are cases in which intending to $\phi$ does not promote $\phi$-ing. In these cases, a reason to $\phi$ is not a reason to intend to $\phi$, on this view. Thus the Special Hypothesis has an important advantage over its main alternative.

Before moving on, we note one objection to this argument. We claimed that acting for a reason entails acting on an intention held for a reason. This claim is reminiscent of the "Simple View," that intentionally $\phi$-ing entails intending to $\phi$, and so might be thought to face similar objections. For instance, Bratman suggests that foreseen but unintended consequences can be intentional: a mara-

18 It may not be appropriate to intend to $\phi$ for the reason that $p$, if $p$ is an outweighed reason to $\phi$. However, it will be still be appropriate to treat $p$ as a reason to intend to $\phi$. For instance, you might consider $p$ in deliberation about whether to $\phi$. Since practical deliberation aims at intention (see section 2.3), you thereby treat $p$ as bearing on whether to intend to $\phi$. More generally, if you treat $p$ as bearing on reasoning that aims at a response $R$, you treat $p$ as bearing on $R$. 
thon runner might intentionally wear down the soles of their shoes, despite not intending to do so, if they are aware that they are doing so. ${ }^{19}$ However, whether or not this is right, the case is no counterexample to our claim, since it is clear that the runner does not run down the soles of their shoes for a reason.

Bratman's central argument against the Simple View turns on his video-game example. Here you are playing a game in which you simultaneously try to hit two targets-using each hand to guide a missile-although you know you cannot hit both. Bratman suggests that if you hit one of the targets - target 1-you do so intentionally, although you did not intend to hit target 1 . Here again, we suggest, it is dubious that you hit target 1 -as opposed to hitting one of the targets-for a reason. But it is also unclear that you do not intend to hit target 1. As others have observed, you are guided by a motivational state with the functional role of intention. We might thus take the case as one in which it is rational to have inconsistent intentions. ${ }^{20}$ Either way then, the video-game example is not a compelling case of acting for a reason without acting on an intention held for a reason. ${ }^{21}$

\subsection{Reasons and Reasoning}

Our second argument aims to provide support for the Special Hypothesis through attention to the way reasons feature in reasoning. In theoretical reasoning, you aim to settle on a view of what is true - to form a belief. But you do this by considering the question of what is true-or, more specifically, of whether, say, it will rain. Thus you consider evidence bearing on this question-e.g., that clouds are gathering. If, on the basis of this evidence, you answer the question affirmatively, you thereby believe it will rain. But you do not need to think about this belief-you can just think about the prospects of rain. ${ }^{22}$

19 Bratman, Intentions, Plans, and Practical Reason, 123.

20 McCann, "Settled Objectives and Rational Constraints"; and Kolodny, "The Myth of Practical Consistency."

21 Hornsby ("On What's Intentionally Done") and Heuer ("Intentions and the Reasons for Which We Act") offer putative cases of acting for reasons without acting from an intention. Hornsby focuses on "emergency cases." If a snowball is about to hit you, she suggests, you might catch it for a reason (that it is about to hit you) without intending to do so. However, forming an intention need not take long or precede the start of action. If catching the ball is not a mere reflex-if you meant to do it - then it does seem that you must have intended to do it (cf. Heuer, "Reasons to Intend"). Other putative cases involve intentions that would be in some way counterproductive. Since such cases might also be thought of as counterexamples to the Special Hypothesis, we discuss them later (section 3 ).

22 You can also revise an attitude as a result of higher-order reasoning about it, e.g., by considering whether your evidence is sufficient to justify belief. But in doing so you most directly revise your higher-order attitudes. It is a further step to revising your first-order attitude. 
In practical reasoning, you aim to settle on a course of action-to form an intention. But you do this by considering the question of what to do-or, more specifically, of whether, say, to go to the pub. Thus you consider factors bearing on this question-e.g., that your friends are at the pub. If, on the basis of such factors, you answer the question affirmatively, you thereby intend to go to the pub. But you do not need to think about this intention-you can just think about the pros and cons of going to the pub. ${ }^{23}$

In both theoretical and practical reasoning, then, there is a distinction between a response to which the reasoning leads and the object of that response. In the theoretical case, the response is a belief and its object is a proposition. In the practical case, the response is an intention and its object is an act type. Thus, as far as their role in reasoning goes, practical reasons seem to stand to intentions, rather than to act types, as theoretical reasons stand to beliefs; they stand to act types as theoretical reasons stand, not to beliefs, but to propositions. In the theoretical case, it is clear that what reasons support is fundamentally beliefs, not propositions. If we take their role in reasoning to be an important aspect of the nature of reasons, then, we should regard practical reasons as fundamentally supporting intentions rather than act types. In doing so we get an attractive, unified picture of how (fundamental) reasons feature in reasoning: a reason for a response is a premise of good reasoning that concludes in that response, reasoning that is about the object of the response. By contrast, if we regard practical reasons as fundamentally supporting act types, then we find deep differences between practical and theoretical reasons in respect of the way they relate, in reasoning, to the responses they support. Such differences seem hard to reconcile with the idea that their role in reasoning is an important aspect of the nature of reasons.

Our argument here might seem to ignore the Aristotelian thesis that the conclusion of practical reasoning is an action. ${ }^{24}$ However, the central alternative to the Special Hypothesis is that practical reasons fundamentally support act types-i.e., types of events or processes that can but need not be intentional. But if the Aristotelian thesis is right, intentional actions can be conclusions of practical reasoning. Mere actions cannot be conclusions of practical reasoning

23 In characterizing practical reasoning this way, we do not deny that there is such a thing as reasoning about what you ought or have reason to do. We class this as theoretical reasoning, although it can — and should but does not always-inform practical reasoning (cf. Broome, Rationality through Reasoning, 250; Harman, Change in View, 77). Nor do we deny that in practical reasoning you might also aim to act-see below (this section).

24 For discussion, see Fernandez, "Practical Reasoning"; Dancy, Practical Shape, 4; Tenenbaum, "The Conclusion of Practical Reason"; and Paul, "The Conclusion of Practical Reasoning." 
by anyone's lights. Irrespective of the Aristotelian thesis, then, we can conclude that practical reasons are not fundamentally reasons for mere actions, and thus that the Special Hypothesis should be preferred to its central alternative. ${ }^{25}$

\section{OBJECTIONS AND REPLIES}

We have made a prima facie case for the Special Hypothesis. We now turn to considering some objections. First, we will consider the objection that the Special Hypothesis wrongly puts the focus of our practical lives on intention rather than action (section 3.1). Second, we will address some putative counterexamples: cases where it might seem plausible to attribute a reason for action but not a reason for intention (section 3.2). Third, we will consider an objection to what we earlier granted is an implication of the Special Hypothesis: that rational criticizability for action depends on rational criticizability for intention. In some cases, it might seem, your actions make you rationally criticizable regardless of your intentions (section 3.3).

\subsection{The Wrong Focus?}

Much of our ordinary practical deliberation, our talk about practical reasons, and our practices of holding each other responsible focus on actions rather than intentions. The Special Hypothesis might seem incompatible with this fact. In taking reasons to act to hold in virtue of reasons to intend, it might seem to give practical reasons the wrong focus, or to suggest that what ultimately matters is what we intend rather than what we do.

However, this concern is misguided. First, reasons for intention are provided by features of actions - for instance, what gives me a reason to intend to go the pub is that going to the pub allows me to see my friends. It is thus not surprising that these features should be the focus of attention in practical deliberation, just as evidence for propositions, rather than beliefs as such, is the focus of ordinary theoretical deliberation. Second, practical deliberation in its basic form is framed by the question of what to $d o$, rather than what to intend, just as theoretical deliberation is framed by the question of what is the case, rather than what to believe. We form intentions in deliberation by answering the question of what to do, just as we form beliefs in deliberation by answering the question of what is true. Third, the Special Hypothesis does not entail that what we intend matters more than how we act. It is a claim about what is metaphysically fundamental,

25 We thus acknowledge that our argument here might be used to support the view that practical reasons are fundamentally for intentional actions. But this would require a defense of the Aristotelian thesis. 
not about what is more important, or what we have more reason to care about. It might be that what matters most is how we act, even though reasons to act derive from reasons to intend, and even though we are criticizable for our actions only insofar as we are criticizable for our intentions.

\subsection{Reasons to Act without Reasons to Intend?}

Some philosophers hold that there are reasons to act that are not reasons to intend. We will discuss two common kinds of examples.

\subsubsection{Pointless Intentions}

Heuer suggests that, if you will do something regardless of whether you intend to do it, then you can have reasons to do it but no reasons to intend it. ${ }^{26} \mathrm{Her}$ examples include reasons not to kill and reasons not to go into space without a spacesuit. The thought seems to be that since you are already going to do the thing there is no point in forming the intention. Examples need not be limited to omissions: for instance, you might have reason to exercise today but since you will get exercise by walking to work, you need not intend to exercise. ${ }^{27}$

But this is not convincing. Heuer's claim here must be that you have no reason for such intentions. But suppose you deliberate about whether to kill someone, whether to go into space without a spacesuit, or whether to exercise today. Clearly, there are relevant considerations that might rationally lead you to intend not to kill anyone, not to go into space without a spacesuit, and to exercise. You would be making no mistake in basing such intentions on these considerations. In doing so, you would be treating them as reasons for so intending. But, again, something that can be appropriately treated as a reason is one. So, even if you are not required to have these intentions, it is not true that you lack reasons for them.

Any impression to the contrary may be due to a tacit assumption that reasons for intentions are instrumental from reasons to act. But, as we explained in section 1, this is a substantive view, and it is one that the foregoing considerations count against. In deliberation about whether to $\phi$, it can be fine to base an inten-

Heuer suggests that habitual actions might also be examples ("Reasons to Intend"). However, as she allows, it is less clear that action from habit is done without intention. We therefore focus on the clearer examples. For discussion of habitual action see Owens, "Habitual Agency." We take the points in this section to also answer further putative counterexamples that could be drawn from Heuer's discussions, including cases in which you have a reason to do something but it does not matter whether you do it intentionally ("Reasons to Intend," 877 ), and cases where a complex action would be impeded by intending each part of it ("Intentions and the Reasons for Which We Act," 306). 
tion to $\phi$ on the worthwhile features of $\phi$-ing, even if intending does not make it more likely that you will $\phi$, because you are going to $\phi$ anyway.

Another potential source of confusion might be a failure to distinguish reasons for intending to $\phi$ from reasons for deliberating about whether to $\phi$. You may have no reason to deliberate about, say, whether to kill. Even if so, it does not follow that you have no reason to intend not to kill. It is a general feature of reasons for attitudes that you can have them even though you have no reason to deliberate. Deliberation demands time and resources that you should invest carefully by directing them to important questions that cannot be left to quick and automatic cognition. You have reasons bearing on many questions that do not call for this investment.

Heuer's argument thus fails. But her examples also form the basis for a different objection to the Special Hypothesis. Even if it is accepted that there are reasons to intend not to kill and not to go into space without a spacesuit, there still seems to be a difference in the overall normative status of these intentions and the corresponding omissions. You ought not go into space without a spacesuit and you ought not kill. But it is okay not to intend these things. And since what you ought to do is, very plausibly, determined by reasons, it follows that there must be reasons to act that do not derive from reasons to intend-for otherwise, the overall status of actions and the corresponding intentions could not come apart.

However, this argument is too quick. If you ought to $\phi$ but need not intend to $\phi$, this need not be because there are reasons to $\phi$ that are not reasons to intend to $\phi$. Indeed, on the face of it, this is not what is going on in these cases. The factors that seem to make it okay not to intend not to kill, and not to intend not to go into space without a spacesuit, are that forming these intentions may require deliberation or conscious attention. This is a use of valuable cognitive resources, which is here a cost that is not compensated for by the need to form an intention. By contrast, the actions of not killing, and not going into space without a spacesuit, do not require deliberation or conscious attention. These factors - the costs of deliberation and attention-are not plausibly understood as reasons to $\phi$ that are not reasons to intend to $\phi$. For instance, that forming an intention not to kill would be costly is not a reason not to kill.

How should we understand these factors and the role they play in explaining the overall status of action and intention? One possibility is that they are reasons against intending to $\phi$ that are not reasons against $\phi$-ing. The Special Hypothesis is compatible with the existence of such reasons, since it takes reasons for and against acting to be reasons for intending (to act or not to act). However, an appeal to such reasons might seem in tension with the way we have argued for 
the Special Hypothesis. ${ }^{28}$ Fortunately, there are other possibilities. Perhaps such factors affect the overall status of intention indirectly by providing reasons to form no intention on the matter. Or perhaps it remains true in these cases that you ought to intend, but it is also true that you ought not deliberate, and will not intend unless you deliberate. If so, you may not be criticizable, even though you lack an intention you ought to have.

Each of these suggestions offers a way to explain seeming differences between the overall statuses of actions and intentions without appealing to reasons for action that are not reasons for intention. Properly assessing them would require an account of how considerations determine what you ought to do and intend, something we cannot provide here. For present purposes the point is just that it is only on a non-mandatory, and indeed implausible, treatment of the target cases that they represent counterexamples to the Special Hypothesis.

\subsubsection{Self-Undermining Intentions}

Sometimes an intention to act can be self-undermining, in the sense that acting on that intention is incompatible with doing what it is an intention to do. For example, if you intend to act modestly then you will fail, since acting modestly is incompatible with acting on such a self-regarding intention. Similarly, acting spontaneously seems incompatible with acting on an intention to be spontaneous. Heuer suggests that in these cases, too, you can have reason to act but no reasons to intend to act. ${ }^{29}$

But here we need to be careful about exactly what reasons it is plausible to attribute to agents. Take modesty. You can have a reason to do what would in fact be modest in a particular situation-to share credit for some achievement, say. And in doing so you might manifest the virtue of modesty. But the reason to act that way will not be that doing so is modest. It will be, for example, that others contributed to the achievement and should get due credit. Nor will this, or any other consideration, be a reason for doing what is modest as such. It will just be a reason for whatever the act type is, e.g., sharing credit. And it will also

In particular, our second argument takes reasons to be potential premises of reasoning and practical reasoning to be reasoning about what to do (section 2.2). It is not clear how reasons against intention that are not reasons against acting could feature in such reasoning. For relevant discussion, see Schroeder, “The Ubiquity of State-Given Reasons”; Hieronymi, "The Use of Reasons in Thought (and the Use of Earmarks in Arguments)"; and Shah and Silverstein, "Reasoning in Stages."

29 Heuer, "Reasons to Intend." There are also cases where intending to act undermines the putative reason to act-as when you will get a reward for falling over, but only if you do so unintentionally. We would treat such cases in the same way, so we do not discuss them separately. 
be a reason for intending this act type. So there are no plausible reasons here that constitute counterexamples to the Special Hypothesis.

This is not to deny that there are modesty-related reasons. For instance, you can have reasons to want to be modest, and to cultivate your modesty. But the intention to cultivate your modesty is not self-undermining.

What about spontaneity? We can say similar things. A "reason to do something spontaneous" might be a reason to choose certain sorts of options in your situation. Or it might be a reason to choose without deliberating at length. There are also reasons to desire and cultivate spontaneity. None of these responses involve self-undermining intentions. There is thus no obvious need to posit reasons that would be counterexamples to the Special Hypothesis. ${ }^{30}$

We take this way of treating putative reasons for modesty and spontaneity to be plausible on its face. Note that it is also supported by the response constraint: the condition that reasons must be such that they can be responded to (section 2.1). If the intention to $\phi$ would be self-undermining, a reason to $\phi$ cannot be responded to. ${ }^{31}$

\subsection{Criticizability}

Reasons matter. When they are conclusive, you are ordinarily criticizable for failing to comply with them. As noted in section 1, the Special Hypothesis seems to imply that you are rationally criticizable for your actions only insofar as you can be rationally criticized for your intentions. We suggested that this implication is plausible.

This might be doubted. Suppose that you promise to feed your neighbor's cat. If all else is equal, this gives you conclusive reason to feed your neighbor's cat. And so, if all else is equal, you will be criticizable if you fail to feed your neighbor's cat. This might seem to be so regardless of your intentions. It is not enough

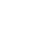

Cf. Smith, "The Ideal of Orthonomous Agency, or the How and Why of Buck-Passing," 62-63.

For further relevant discussion, see Paakkunainen, "Can There Be Government House Reasons for Action?" Pink offers a different kind of counterexample to the Special Hypothesis (The Psychology of Freedom). He argues that the fact that you now intend to $\phi$ at a later time $t$ can itself generate reasons to $\phi$ at $t$, since it makes it likely that between now and $t$ you will stake things on your $\phi$-ing at $t$ (e.g., by making plans whose success depends on your $\phi$-ing at $t$, and inviting others to do so; cf. Kolodny, "The Myth of Practical Consistency"). Yet the mere fact that you have this intention cannot give you a reason to have it. While we lack the space to discuss this in detail, we suggest that the fact, if it is one, that things will be staked on your $\phi$-ing at $t$ is a reason both for $\phi$-ing and for intending to $\phi$. That seems plausible: if failing to $\phi$ threatens disaster, then you have a reason to intend to $\phi$. However, if you are deliberating about whether to $\phi$ then you do not yet have the settled intention to $\phi$, so no reasons of the sort Pink describes are generated. 
just to intend to feed the cat: you also have to execute this intention. Thus the Special Hypothesis does not capture the significance of reasons to act.

This objection requires that there are cases in which you intend as you have conclusive reason to intend, fail to act as you have conclusive reason to act, and thereby merit criticism. In the remainder of this section, we will argue that it is unclear that there are such cases. We will do so by considering different ways in which you might fail to feed your neighbor's cat, despite intending to do so.

Suppose that you now intend to feed the cat but then later change your mind, or forget, and so do not feed the cat. You might then be criticizable for failing to feed the cat, despite having intended to do it. But the Special Hypothesis can explain this. As noted (section 1), reasons are indexed to times, which may be earlier than the time of the response that is called for. You might now have reason to feed the cat later, or you might now have reason to feed the cat now. But you merit criticism for failing to do what you have reason to do only once the time for the response has come. If you have conclusive reason to feed the cat later, then you do not merit criticism just because you are not yet feeding the cat. You merit criticism only if you have conclusive reason to feed the cat now. But in the case at issue, you lack the right intention at the time you are meant to be feeding the cat. Thus the Special Hypothesis can explain why you are criticizable.

This shows that any problematic cases for the Special Hypothesis must be cases in which you fail to act on an intention to act at that very time. ${ }^{32}$ But there might seem to be such cases. You might intend to feed the cat at midnight but fail to do so because you are not aware that it is midnight. Or you might intend to feed the cat at midnight and try to do so but fail—perhaps something prevented you, or perhaps you needed a bit of luck to succeed, which was not forthcoming.

To address such cases, we need the notion of having control over whether you $\phi$. Roughly, where $\phi$-ing is an act type, you have control over whether you $\phi$ if trying to $\phi$ (or not to do so) will ensure that you $\phi$ (or do not $\phi$ ). You lack control over whether you $\phi$ if this is not so. If you lack control over whether you $\phi$ then it is not up to you whether you $\phi$. This might be because you cannot $\phi$ at all, or cannot but $\phi$. More interestingly, it might be because, although you can $\phi$, trying to $\phi$ will not ensure that you do so-you might need a bit of luck. ${ }^{33}$

32 Note that such an intention need not be a present-directed intention, i.e., an intention directed at the present, conceptualized as such.

33 For trying to $\phi$ to ensure that you $\phi$ is not for it to be necessary that, if you try to $\phi$, you $\phi$. A weaker relation is required-perhaps that in nearby worlds you $\phi$ if you try to $\phi$. Note also that by "trying" we mean "trying appropriately." This is because $\phi$-ing is not necessarily out of your control if you might fail to $\phi$ despite a weak attempt, or because you try "too hard," or in the wrong way. We take it that failed attempts of this sort will reflect potentially criticizable features of underlying attitudes (cf. the discussion of tracing in the main text). It will, 
Consider now the case in which you intend to feed the cat and try to do so but fail. In this case, feeding the cat was not under your control. But, ordinarily, if you lack control over whether you do something, you cannot be rationally criticized for failing to do it (though you might be criticized for failing to try). The fact that it was not up to you whether to feed the cat excuses you for failing to do so, so long as you tried your best.

Of course, a lack of control does not always excuse. In particular, if you are responsible for the lack of control-perhaps because you are drunk, or failed to take earlier opportunities to ensure that feeding the cat would later be under your control - then you may still be criticizable. But this is an example of the familiar phenomenon whereby current criticizability can be traced to earlier mistakes - as when the drunken driver is criticizable for hitting the pedestrian, not because he could have done anything about it at the time, but because he decided to drive when drunk. ${ }^{34}$ It is plausible that criticizability of this sort requires the agent to have had erroneous intentions at the earlier time.

The phenomenon of tracing shows the need for an important clarification of our account. While rational criticizability for failing to $\phi$ must derive from rational criticizability for (lacking) some intention, it need not be the intention to $\phi$. It may derive from criticizability for lacking an intention to $\psi$, where $\psi$-ing would have facilitated $\phi$-ing. We do not take this to be a problem for the Special Hypothesis, but rather a plausible upshot that emerges when we combine it with considerations about tracing. ${ }^{35}$

What about a case in which you to fail to act because of ignorance-e.g., of what the time is, or of which cat is your neighbor's? Well, if you are unaware of your ignorance or you lack control over whether you correct it, then you also lack control over whether you feed the cat. You might luckily manage to do it, but trying does not ensure that you will. Again, then, if you fail to feed the cat, you will not merit criticism, unless you are responsible for your lack of control.

If, on the other hand, you are aware of your ignorance and it is under your control whether to correct it, then, at least if you are rational, you will correct your ignorance and try to feed the cat. If you do not, that will be because there is

of course, be a difficult matter to specify precisely the required notion of trying. For relevant discussion, see, e.g., Maruśič, Evidence and Agency, chs. 1, 6; and Portmore, "Opting for the Best," ch. 3 .

34 E.g., Fischer and Tognazinni, "The Truth about Tracing."

35 We take these points to help with cases where an agent is rationally criticizable for an unintended outcome brought about through negligence or recklessness. Although in such cases the agent does not intend the bad outcome, they will be criticizable only if their intentions are criticizable in some respect. 
an intention that you lack, e.g., to correct your ignorance, and your criticizability for failing to feed the cat will be traceable to it.

The qualification "if you are rational" suggests that there might be a further kind of case. Might you not intend to feed the cat at midnight, know that it is midnight, have it under your control whether to feed the cat, and yet fail to do so because you are irrational_ — perhaps, for instance, you are weak willed, or lazy, or lose your nerve?

This worry can be reinforced with a different example. Suppose you have conclusive reason to get out of bed now-you are already running late. Still, even if you intend to get out of bed you might not. And not because of ignorance or a lack of control - rather, you just fail to get yourself to do what you intend. This might seem irrational — and thus criticizable_-but nonetheless possible, indeed common.

We think that paying attention to time helps here too. An intention "to get out of bed" could either be an intention to get out of bed at a later (though perhaps imminent) time, or an intention to be getting out of bed right now. As we have seen, cases in which you have an intention to act at a later time are not problematic. You can only be criticized for failing to act on a reason to act once the time for action has come.

But could you intend to be getting out of bed now and yet not be getting out of bed now? We think it is hard to make sense of this possibility, assuming that getting out of bed is under your control. As suggested earlier (section 1), it is plausible that there is a necessary connection between present-directed intention and trying: if you are not now trying to $\phi$ then you do not intend to be $\phi$-ing, even if you think you do, and even if you did until a moment ago. ${ }^{36}$ But if it is in your control to move now, and you try to move, you will move. In support of this, note that the conventional expression of a present-directed intention to $\phi$ is "I am $\phi$-ing." If you are aware you are not moving, and you are not even trying to move, you cannot sincerely say "I am getting out of bed."

We conclude that there are no clear cases in which you intend as you have conclusive reason to intend (at the appropriate time), fail to act as you have

Cf., e.g., Bratman, Intentions, Plans, and Practical Reason, 16; Broome, Rationality through Reasoning, 151-52; O'Shaughnessy, “Trying (as the 'Mental Pineal Gland')," 380-83; and McDowell, "Some Remarks on Intention in Action," 3. Asarnow takes the phenomenon of not getting out of bed to be a counterexample to claims of this sort ("On Not Getting Out of Bed"). While we agree with Asarnow that there is a familiar experience of, as he puts it, "irrationally dawdling in bed," we think that it is not obvious that it involves a failure to act on an intention to be getting out of bed rather than a failure to act on a series of intentions to get out of bed imminently. Unfortunately we lack the space to engage with Asarnow's discussion in more detail. 
conclusive reason to act, and are thereby criticizable. Thus we have not seen a compelling case that the Special Hypothesis cannot explain the significance of reasons for action. Rather, it seems that in all cases in which you are rationally criticizable for failing to act, there is also a problem with your intentions. The Special Hypothesis can thus maintain that this explains why you are criticizable.

\section{UPSHOTS}

We have been defending the Special Hypothesis, the claim that reasons for action are fundamentally reasons for intention. After some discussion of what the claim amounts to, we presented two arguments for it and responded to several objections. This also amounts to a case for the General Hypothesis, that all reasons are fundamentally reasons for attitudes. As we began by noting, the General Hypothesis runs contrary to much theorizing about reasons. It thus has upshots for a range of issues. In closing, we indicate some of these.

Some theorists hold that reasons are always grounded in some value possessed or promoted by the responses they support. ${ }^{37}$ This claim has prima facie plausibility when applied to reasons for action. When you have a reason to go to the pub or donate to charity, that is plausibly because of some good that is likely to come of it. The claim is less plausible when applied to reasons for attitudes: it seems you have reasons to believe truths and fear dangers even when no good will come of it. However, if the Special Hypothesis is correct, then the claim even gets reasons for action importantly wrong. According to the Special Hypothesis, reasons for action are fundamentally reasons for intention. And reasons for intention are not based in the value of intending. They might often be based in the value of the action intended, but even then the reasons for intending need not be conditional on the intention's promoting this value. As we saw with the case of intending not to enter space without a spacesuit, you can have reasons to intend even when intending does not promote doing what you intend, and so need not itself be of value. Thus, even reasons for action are not grounded in the value of the responses they fundamentally support.

This illustrates how theorizing about reasons can be shaped by the sorts of examples we start from. If we start from action as the paradigm case, the view that reasons are grounded in value will seem plausible. However, when we consider reasons for attitudes, it seems more natural to explain them in terms of their role in good reasoning or the fittingness conditions of attitudes. ${ }^{38}$ If the General Hy-

37 E.g., Maguire, “The Value-Based Theory of Reasons"; Finlay, Confusion of Tongues; and Wedgwood, The Value of Rationality.

38 Cf. Hieronymi, “The Wrong Kind of Reason"; Howard, “The Fundamentality of Fit”; 
pothesis is correct, accounts of the latter sort have better prospects for capturing the fundamental nature of reasons.

Another upshot concerns the connections between reasons and control. When we focus on actions, we seem to find connections between reasons and voluntary control. You can have reasons to go to the pub but not to, say, win the lottery, because only the former is under your voluntary control. And it is plausible that you are rationally criticizable for not going to the pub only insofar as doing so was under your voluntary control. However, it is not a general feature of reason-governed responses that they are under voluntary control: belief is not under voluntary control, nor is, for instance, desire, admiration, or fear. Nor, importantly, is intention. We do not form and revise intentions by way of intentions to do so. Rather, like other reason-governed attitudes, intention is under a more fundamental, nonvoluntary form of control, in which we directly form and revise our attitudes in response to reasons. ${ }^{39}$ If the General Hypothesis is correct, this suggests that it is this nonvoluntary attitudinal control that is most fundamentally relevant to reasons and rational criticizability. Voluntary control matters for action because it is by executing intentions, and thus exercising voluntary control, that we respond to reasons for actions. But that is an idiosyncratic case, not a paradigmatic one.

More broadly, the General Hypothesis highlights the fundamental role of attitudes in our constitution as rational, responsible, world-engaged agents. Attitudes constitute our orientation toward the world, in which we can get things right or wrong, be justified or not. Our actions change the world in more or less beneficial ways - but it is only insofar as they express or embody our orientation toward the world that they fall within the realm of reason and normativity. ${ }^{40}$

\section{University of Southampton c.mchugh@soton.ac.uk j.way@soton.ac.uk}

McHugh and Way, "Fittingness First"; Setiya, Reasons without Rationalism; and Thomson, Normativity.

Dougherty, Luke Elson, Giulia Felappi, Alex Gregory, Marie Guillot, Grace Helton, Brad Hooker, Yair Levy, Richard Rowland, David Shoemaker, Philip Stratton-Lake, Daniel Whiting, Daniel Wodak, several anonymous referees, and audiences at Cardiff University, Humboldt University Berlin, NYU Abu Dhabi, Ryerson University, Tulane University, the University of Essex, the University of Reading, the University of Southampton, and the University of Zurich. Work on this paper was supported by a fellowship at the Murphy Institute at Tulane University. 


\section{REFERENCES}

Asarnow, Samuel. "On Not Getting Out of Bed." Philosophical Studies 176, no. 6 (June 2019): 1639-66.

—. "Rational Internalism." Ethics 127, no. 1 (2016): 147-78

Bratman, Michael. Intentions, Plans, and Practical Reason. Cambridge, MA: Harvard University Press, 1987.

Broome, John. Rationality through Reasoning. Oxford: Blackwell, 2013.

Dancy, Jonathan. Practical Shape: A Theory of Practical Reasoning. Oxford: Oxford University Press, 2018.

Davidson, Donald. "Intending." In Philosophy of History and Action, Philosophical Studies Series in Philosophy 11, edited by Yirmiahu Yovel, 41-60. Dordrecht: Springer, 1978.

Fernandez, Patricio A. "Practical Reasoning: Where the Action Is." Ethics 126, no. 4 (July 2016): 869-900.

Finlay, Stephen. Confusion of Tongues: A Theory of Normative Language. Oxford: Oxford University Press, 2014.

Fischer, John Martin, and Neal A. Tognazinni. "The Truth about Tracing." Noûs 43 (September 2009): 531-66.

Foley, Richard. The Theory of Epistemic Rationality. Cambridge, MA: Harvard University Press, 1987.

Gibbard, Allan. Wise Choices, Apt Feelings. Cambridge, MA: Harvard University Press, 1990.

Glüer, Kathrin, and Åsa Wikforss. "Against Content Normativity." Mind 118, no. 469 (January 2009): 31-70.

Harman, Gilbert. Change in View: Principles of Reasoning. Cambridge, MA: MIT Press, 1986.

Hedden, Brian. Reasons without Persons. Oxford: Oxford University Press, 2015.

Heuer, Ulrike. "Intentions and the Reasons for Which We Act." Proceedings of the Aristotelian Society 114 (2014): 291-316.

- "Reasons to Intend." In The Oxford Handbook of Reasons and Normativity, edited by Daniel Star, 865-90. Oxford: Oxford University Press, 2018.

Hieronymi, Pamela. "Controlling Attitudes." Pacific Philosophical Quarterly 87, no. 1 (March 2006): 45-74.

- "Reasons for Action." Proceedings of the Aristotelian Society 111 (2011): 407-27.

- "The Use of Reasons in Thought (and the Use of Earmarks in Arguments)." Ethics 124, no. 1 (October 2013): 114-27. 
_ . "The Wrong Kind of Reason." Journal of Philosophy 102, no. 9 (September 2005): 437-57.

Hornsby, Jennifer. "On What's Intentionally Done." In Action and Value in Criminal Law, edited by Stephen Shute, John Gardner, and Jeremy Horder, 55-74. Oxford: Clarendon Press, 1993.

Howard, Christopher. "The Fundamentality of Fit." In Oxford Studies in Metaethics, vol. 14, edited by Russ Shafer-Landau, 216-36. Oxford: Oxford University Press, 2019.

Kavka, Gregory S. “The Toxin Puzzle." Analysis 43, no. 1 (January 1983): 33-36.

Kiesewetter, Benjamin. The Normativity of Rationality. Oxford: Oxford University Press, 2017

Kolodny, Niko. "The Myth of Practical Consistency." European Journal of Philosophy 16, no. 3 (December 2008): 366-402.

—. "Why Be Rational?” Mind 114, no. 455 (July 2005): 509-63.

Lord, Errol. The Importance of Being Rational. Oxford: Oxford University Press, 2018.

Maguire, Barry. “There Are No Reasons for Affective Attitudes.” Mind 127, no. 507 (July 2018): 779-805.

. "The Value-Based Theory of Reasons." Ergo 3, no. 9 (2016): 233-62.

Maruśič, Berislav. Evidence and Agency: Norms of Belieffor Promising and Resolving. Oxford: Oxford University Press, 2015.

McCann, Hugh J. "Settled Objectives and Rational Constraints." American Philosophical Quarterly 28 no. 1 (January 1991): 56-36.

McDowell, John. "Some Remarks on Intention in Action." Amherst Lecture in Philosophy 6 (2011): 1-18. http://www.amherstlecture.org/mcdowell2011/.

McHugh, Conor. "Attitudinal Control." Synthese 194, no. 8 (August 2017): 274562.

- "Judging as a Non-Voluntary Action." Philosophical Studies 152, no. 2 (January 2011) 245-69.

McHugh, Conor, and Jonathan Way. "Fittingness First." Ethics 126, no. 3 (April 2016): 575-606.

O’Shaughnessy, Brian. "Trying (as the 'Mental Pineal Gland')." Journal of Philosophy 70 , no. 13 (July 1973): 365-86.

Owens, David. "Habitual Agency." Philosophical Explorations 20 (2017): 93-108.

Paakkunainen, Hille. "Can There Be Government House Reasons for Action?" Journal of Ethics and Social Philosophy 12, no. 1 (September 2017): 56-93.

Papineau, David. "Normativity and Judgement." Aristotelian Society Supplementary Volume 73, no. 1 (July 1999): 17-43.

Parfit, Derek. On What Matters. Oxford: Oxford University Press, 2011. 
Paul, Sarah K. “The Conclusion of Practical Reasoning." Canadian Journal of Philosophy 43, no. 3 (2013): 287-302.

Pink, Thomas. The Psychology of Freedom. Cambridge: Cambridge University Press, 1996.

Portmore, Douglas W. Commonsense Consequentialism. Oxford: Oxford University Press, 2011.

- Opting for the Best: Oughts and Options. Oxford: Oxford University Press, 2019.

Raz, Joseph. From Normativity to Responsibility. Oxford: Oxford University Press, 2011.

Ryan, Sharon. "Doxastic Compatibilism and the Ethics of Belief." Philosophical Studies 114, nos. 1-2 (May 2003): 47-79.

Scanlon, T. M. What We Owe to Each Other. Cambridge, MA: Harvard University Press, 1998.

Schroeder, Mark. Slaves of the Passions. Oxford: Oxford University Press, 2007.

- "The Ubiquity of State-Given Reasons." Ethics 122, no. 3 (April 2012): 457-88.

Setiya, Kieran. "Intention." Stanford Encyclopedia of Philosophy (Fall 2018). https://plato.stanford.edu/archives/fall2018/entries/intention/.

- Reasons without Rationalism. Princeton: Princeton University Press, 2007.

Shah, Nishi. "How Action Governs Intention." Philosophers' Imprint 8, no. 5 (July 2008): 1-19.

—. "A New Argument for Evidentialism." Philosophical Quarterly 56, no. 225 (October 2006): 481-98.

Shah, Nishi, and Matthew Silverstein. "Reasoning in Stages." Ethics 124, no. 1 (October 2013): 101-13.

Silverstein, Matthew. "Reducing Reasons." Journal of Ethics and Social Philosophy 10, no. 1 (February 2016): 1-22.

Smith, Michael. "The Ideal of Orthonomous Agency, or the How and Why of Buck-Passing." In Thinking about Reasons: Themes From the Philosophy of Jonathan Dancy, edited by David Bakhurst, Margaret Olivia Little, and Brad Hooker, 50-75. Oxford: Oxford University Press, 2013.

Steglich-Peterson, Asbjørn. "How to Be a Teleologist about Epistemic Reasons." In Reasons for Belief, edited by Asbjørn Steglich-Peterson and Andrew Reisner, 13-33. Cambridge: Cambridge University Press, 2011.

Steup, Matthias. “Doxastic Freedom." Synthese 161, no. 3 (April 2008): 375-92.

Tenenbaum, Sergio. “The Conclusion of Practical Reason.” In Moral Psychology, edited by Sergio Tenenbaum, 323-43. Amsterdam: Rodopi, 2007. 
Thompson, Michael. Life and Action. Cambridge, MA: Harvard University Press, 2008.

Thomson, Judith Jarvis. Normativity. Chicago: Open Court, 2008.

Way, Jonathan, and Daniel Whiting. "Reasons and Guidance (or, Surprise Parties and Ice Cream)." Analytic Philosophy 57, no. 3 (September 2016): 214-35.

Weatherson, Brian. "Deontology and Descartes's Demon." Journal of Philosophy 105, no. 9 (September 2008): 540-69.

Wedgwood. Ralph. The Value of Rationality. Oxford: Oxford University Press, 2017.

Williams, Bernard. "Internal and External Reasons." In Moral Luck, 101-13. Cambridge: Cambridge University Press, 1981.

Wilson, George, and Samuel Shpall. "Action." Stanford Encyclopedia of Philosophy (Winter 2016). https://plato.stanford.edu/archives/win2016/entries/ action/. 